PREPARED FOR THE U.S. DEPARTMENT OF ENERGY, UNDER CONTRACT DE-AC02-76CH03073

PPPL-3612

PPPL-3612

UC-70

Ballooning Stability of the Compact Quasiaxially Symmetric Stellarator

by

M.H. Redi, J. Canik, R.L. Dewar, J.L. Johnson,

S. Klasky, W.A. Cooper, and W. Kernbichler

September 2001

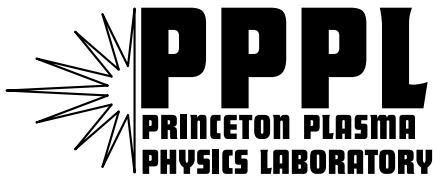

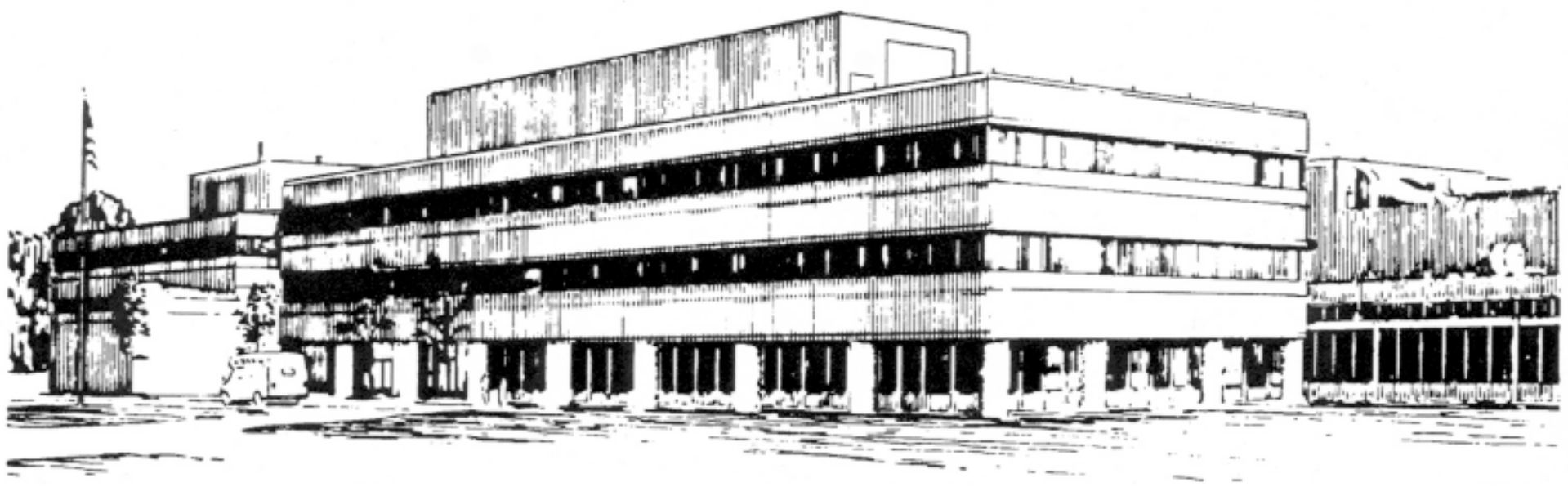

PRINCETON PLASMA PHYSICS LABORATORY PRINCETON UNIVERSITY, PRINCETON, NEW JERSEY 


\section{PPPL Reports Disclaimer}

This report was prepared as an account of work sponsored by an agency of the United States Government. Neither the United States Government nor any agency thereof, nor any of their employees, makes any warranty, express or implied, or assumes any legal liability or responsibility for the accuracy, completeness, or usefulness of any information, apparatus, product, or process disclosed, or represents that its use would not infringe privately owned rights. Reference herein to any specific commercial product, process, or service by trade name, trademark, manufacturer, or otherwise, does not necessarily constitute or imply its endorsement, recommendation, or favoring by the United States Government or any agency thereof. The views and opinions of authors expressed herein do not necessarily state or reflect those of the United States Government or any agency thereof.

\section{Availability}

This report is posted on the U.S. Department of Energy's Princeton Plasma Physics Laboratory Publications and Reports web site in Calendar Year 2001. The home page for PPPL Reports and Publications is: http://www.pppl.gov/pub_report/

DOE and DOE Contractors can obtain copies of this report from:

U.S. Department of Energy

Office of Scientific and Technical Information

DOE Technical Information Services (DTIS)

P.O. Box 62

Oak Ridge, TN 37831

Telephone: (865) 576-8401

Fax: (865) 576-5728

Email: reports@adonis.osti.gov

This report is available to the general public from:

National Technical Information Service

U.S. Department of Commerce

5285 Port Royal Road

Springfield, VA 22161

Telephone: 1-800-553-6847 or

(703) 605-6000

Fax: (703) 321-8547

Internet: http://www.ntis.gov/ordering.htm 


\title{
BALLOONING STABILITY OF THE COMPACT QUASIAXIALLY SYMMETRIC STELLARATOR
}

\author{
M. H. Redi ${ }^{(1)}$, J. Canik ${ }^{(2)}$, R. L. Dewar ${ }^{(3)}$, J. L. Johnson ${ }^{(1)}$, S. Klasky ${ }^{(1)}$, W. A. Cooper ${ }^{(4)}$, W. \\ Kernbichler ${ }^{(5)}$ \\ ${ }^{(1)}$ Princeton Plasma Physics Laboratory, Princeton University, P. O. Box 451, Princeton, NJ \\ 08543
}

${ }^{(2)}$ Department of Electrical and Computer Engineering, University of Wisconsin, Madison, WI 53706

${ }^{(3)}$ Department of Theoretical Physics and Plasma Research Laboratory, The Australian National University, Canberra, ACT 0200, Australia

${ }^{(4)}$ Centre de Recherche en Physique des Plasmas, Ecole Polytechnique Federale de Lausanne, PPB Ecublens, CH-1015, Lausanne, Switzerland

${ }^{(5)}$ Institut für Theoretische Physik, Technische Universität Graz, Petersgasse 16, A-8010 Graz, Austria

E-mail: redi@pppl.gov

The magnetohydrodynamic (MHD) ballooning stability of a compact, quasiaxially symmetric stellarator (QAS), expected to achieve good stability and particle confinement is examined with a method that can lead to estimates of global stability. Making use of fully 3D, ideal MHD stability codes, the QAS beta is predicted to be limited above $4 \%$ by ballooning and high- $n$ kink modes. Here MHD stability is analysed through the calculation and examination of the ballooning mode eigenvalue isosurfaces in the 3-space $(s$, $\left.\alpha, \theta_{k}\right) ; s$ is the edge normalized toroidal flux, $\alpha$ is the field line variable, and $\theta_{k}$ is the perpendicular wave vector or ballooning parameter. Broken symmetry, i.e., deviations from axisymmetry, in the stellarator magnetic field geometry causes localization of the ballooning mode eigenfunction, with new types of non-symmetric, eigenvalue isosurfaces in both the stable and unstable spectrum. The isosurfaces around the most unstable points in parameter space (well above marginal) are topologically spherical. In such cases attempts to use ray tracing to construct global ballooning modes lead to a kspace runaway. Introduction of a reflecting cutoff in $k_{\perp}$ to model numerical truncation or finite Larmor radius (FLR) yields chaotic ray paths ergodically filling the allowed phase space, indicating that the global spectrum must be described using the language of quantum chaos theory. However, the isosurface for marginal stability in the cases studied are found to have a more complex topology, making estimation of FLR stabilization more difficult.

\section{Introduction}

Understanding of ballooning mode stability boundaries may lead to performance improvement of toroidal devices through control of disruptions. Toroidally localized ballooning modes have been found as precursors to high beta disruptions on TFTR arising in conditions of $n=1$ kink mode asymmetry. Recent optimization has shown that magnetohydrodynamic stability as well as good particle confinement are likely to be achievable in the proposed National Compact Stellarator Experiment (NCSX), a compact, quasiaxially symmetric stellarator (QAS) 
for values of the plasma near $\beta=4 \% .^{1} \quad$ The configuration, with a major radius of $1.42 \mathrm{~m}$, an aspect ratio of 4.4, a toroidal magnetic field 1.2-1.7 $\mathrm{T}$ and $6 \mathrm{MW}$ of neutral beam heating, is stable to MHD instabilities, with $\beta$ expected to be limited by high- $n$ kink and ballooning modes. This paper describes the ballooning eigenvalue isosurfaces obtained for NCSX above the design beta, the first step in examining kinetic stabilization of the ballooning beta limit using a hybrid WKB approach. 2,3

\section{Eigenvalue Isosurfaces of the Quasiaxially Symmetric Stellarator}

The VVBAL module of the TERPSICHORE code suite ${ }^{4}$ has been used to calculate the ballooning instability for several NCSX equilibria (Fig. 1) above the design point $(\beta=4.1 \%$ ). The displacement of the flux surface grows with growth rate $\gamma ; \xi \propto \exp (i \omega t) \propto \exp (\gamma t)$. We define the eigenvalue $\lambda=-\omega^{2}$; positive values of $\lambda$ denote instability, while negative values denote stability. For $\beta=4.3 \%$ and $\beta=6.8 \%$ we have assembled a datacube of ballooning eigenvalues $\lambda\left(s, \alpha, \theta_{k}\right)$, of size $(126,101,21)$. $\quad \mathrm{s}$ is the toroidal flux, $\alpha$ is the field line variable. Roughly, within $\pm \pi$, the ballooning parameter $\theta_{k}$ determines where the eigenfunction is a maximum. Figure 2 shows the plasma iota of the two equilibria. These are weak shear plasmas, with vanishing shear near the edge.

The isosurfaces of $\lambda$ constrain the possible trajectories of rays of the eikonal equation. Consequently they help determine the quantization conditions that are used to find the maximum wave vector, and thereby kinetic stabilization of the ballooning mode at the beta limit. The QAS isosurfaces are found to exhibit unusual topologies for the two equilibria. Distinct and unique structures at $4.3 \% \beta$ occur for different ranges of $\lambda$ in the stable spectrum for Alfven waves: a) at $\lambda=-0.15$, a helical structure is found near the plasma edge, rotating about an axis nearly parallel to the $\theta_{k}$ axis and open toward the plasma center; b) at $\lambda=-0.45$, cylinders are found nearly constant in $\theta_{k}$, localized in $s$ and $\alpha$. At $\beta=6.8 \%$, similar structures in the stable spectrum occur, although more global in extent.

The unstable spectra are less complex, consisting primarily of planes and topologically cylindrical and spherical isosurfaces near the outer edge of the plasma, where shear goes to zero and the instability is more easily driven. In general, there is a weak dependence on the ballooning angle $\theta_{k}$, stronger dependence on the field line $\alpha$ and quite strong dependence on the radial parameter $s$. At $\beta=4.3 \%$ topologically spherical isosurfaces are found for the maximum eigenvalues, indicative of strong quantum chaos. ${ }^{2}$ This description "quantum chaos" for the paths of rays of the ballooning equation does not mean that the plasma behavior is chaotic, but that the mathematics of a quantum chaotic scattering problem can be used for instabilities for high values of $\lambda$, far above the marginal point of the equilibrium. As the eigenvalue $\lambda$ drops to zero, isolated unstable cylindrical and planar isosurfaces conjoin and the isosurface is no longer simply connected. At $6.8 \% \beta$, the surfaces break up at maximum eigenvalues. The configuration is Mercier stable at both values of $\beta$. Comparison with a related tokamak shows that the rich structure of the QAS spectra arise from the complexity of the magnetic configuration.

\section{Finite Larmor Radius Stabilization of the Ballooning Mode at the Beta Limit}

In practice, only finite- $n$ modes can be unstable due to finite ion Larmor radius (FLR) stabilization, so that the infinite- $n$ ballooning calculation may underpredict the actual MHD limiting beta. The validity of the hydrodynamic, fluid model for MHD breaks down and kinetic corrections are required if the condition $\left(k_{\perp} \rho_{i}\right)^{2}<<1$ is not satisfied. Here $k_{\perp}$ is the wave vector 
perpendicular to the field line, and $\rho_{i}$ is the ion Larmor radius, which for the QAS is $\sim 1 \mathrm{~cm}$. Finite- $n$ ballooning mode stability calculations with a 3D linear MHD code for a two-field period QAS configuration showed that the finite- $n$ ballooning modes $(n \sim 20)$ are significantly more stable than the infinite- $n$ results. For $\mathrm{H} 1$ and for a 10 field period stellarator, finite- $n$ ballooning modes have been examined by applying the WKB ballooning formalism and semi-classical quantization or quantum chaos theory, depending on the topology of the isosurfaces. ${ }^{2,3}$ Near the QAS beta limit the ballooning rays at the marginal point $(\lambda=0)$ will propagate on an isosurface having a new and complex topology, determining $k_{\perp}$. It remains to be determined whether the ray orbits are regular, and how to use the orbit results to estimate $k_{\perp}$ via the Einstein-Brillouin-Keller semiclassical quantization or the quantum chaos method. ${ }^{3}$

\section{Anderson localization}

Toroidal localization of the ballooning mode in stellarator plasmas has been identified for $\mathrm{H}^{3}{ }^{3}$, LHD ${ }^{5}$ and $\mathrm{HSX}^{6}$. This localization is analogous to Anderson localization ${ }^{7}$ of electron eigenfunctions in condensed matter. For the QAS, we find that localization increases toward the edge of the plasma where the ballooning potential is increasingly aperiodic (Fig. 3) and there is stronger effective field ripple (Fig. 4). Each flux surface has a different shape, changing the poloidal angle, $\theta_{k}$, at which the eigenfunction is maximized. The most localized modes in this geometry occur in the region where global magnetic shear is weakest, including at the shear reversal surface itself, demonstrating the existence of Anderson localization in the QAS.

\section{Conclusion}

We find Anderson localization of the ballooning mode in the QAS and have obtained eigenvalue isosurfaces with which to examine kinetic stabilization of $\beta$. A new method of regularizing the eigenfunction to estimate $k_{\perp}$ may be needed for the QAS at the beta limit, because of the complex topology of the marginal point isosurfaces. ${ }^{3}$ The WKB method of high $n$ ballooning stability calculations may break down for the QAS at the marginal point, requiring fully 3D, ideal or resistive MHD codes such as CAS3D, TERPSICHORE and Spector3D. Finally, while drift orbit optimization has allowed neoclassical particle transport to be kept low in the QAS, the detailed relationships between ballooning mode isosurface structures and drift mode growth rates need to be examined. Microinstability-based drift wave calculations based on radially local ballooning representations for LHD and QAS configurations can already predict drift mode growth rates in the electrostatic limit ${ }^{8}$. The toroidal dependence of anomalous transport will be sensitive to the localized ballooning structures. An investigation of stable magnetosonic structures would require relaxation of the incompressibility condition and integration of a $4^{\text {th }}$ order system of equations. Further work will be needed in all these aspects of stellarator configuration design.

1. A. H. Reiman, et al. Phys. Plas. 8, 2083 (2001).

2. R. L. Dewar, P. Cuthbert, R. Ball, Phys. Rev. Lett. 86, 2321 (2001).

3. P. Cuthbert, R. L. Dewar, Phys. Plas. 7, 2302 (2001). R. L. Dewar, private communication.

4. W. A. Cooper, Plas. Phys. Cont. Fus. 34 (1992) 1011.

5. J. Chen, N. Nakajima, M. Okamoto, Phys. Plas. 6 (1999) 1562.

6. C. Hegna, S. Hudson, Phys. Rev. Lett. 87, 035001 (2001).

7. P. W. Anderson, Phys. Rev. 109, 1492 (1958).

8. G. Rewoldt, et al. Phys. Plas. 7 (2000) 4942. G. Rewoldt, et al. Phys. Plas. 6 (1999), 4705.

* Research supported by U. S. DOE Contract DE-AC02-76CH0373. 


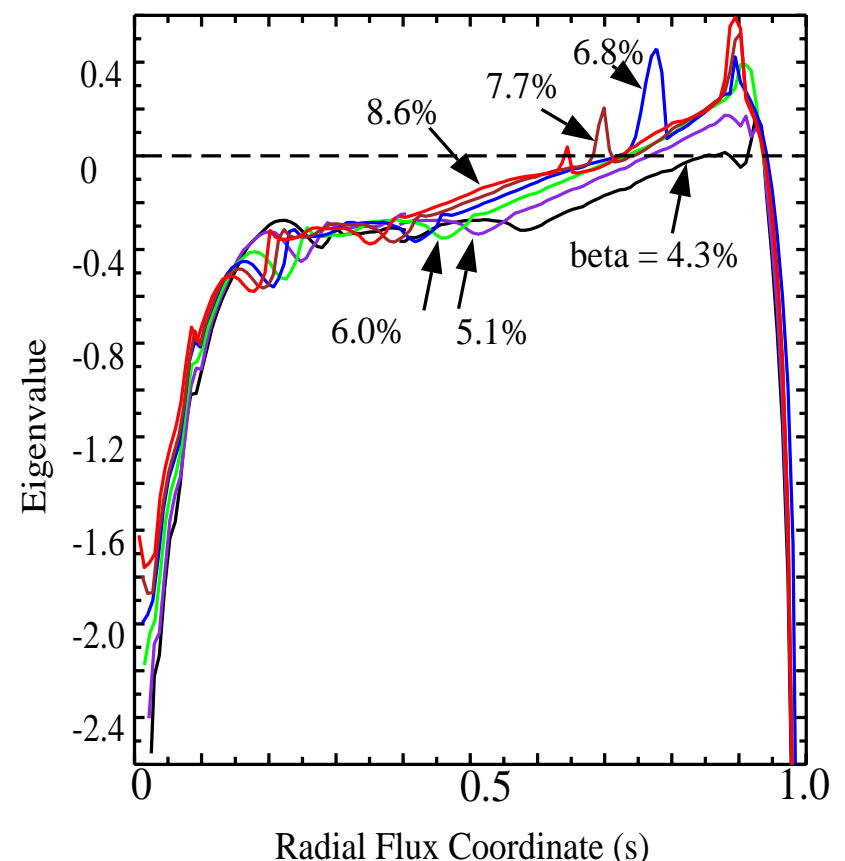

Figure 1. Ballooning eigenvalues for NCSX above the design point. $\alpha=0, \theta k=0$.
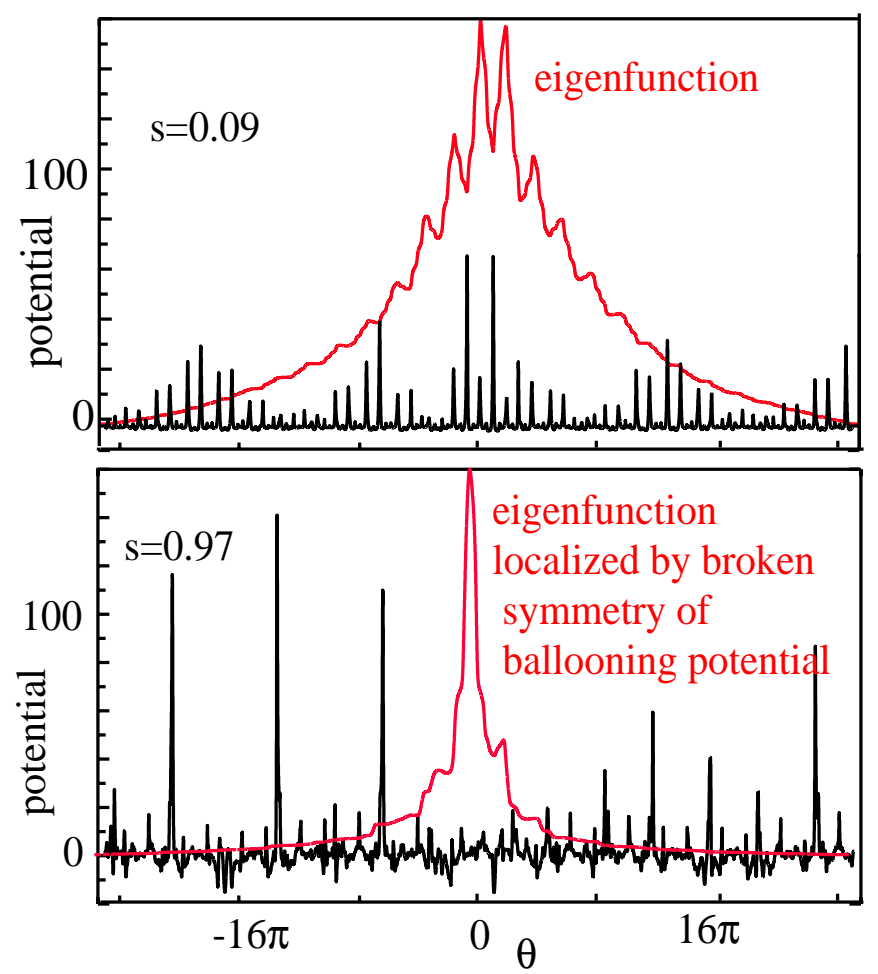

Figure 3. Eigenfunction localization in poloidal angle near the plasma edge, labeled by s, the edge normalized toroidal flux.

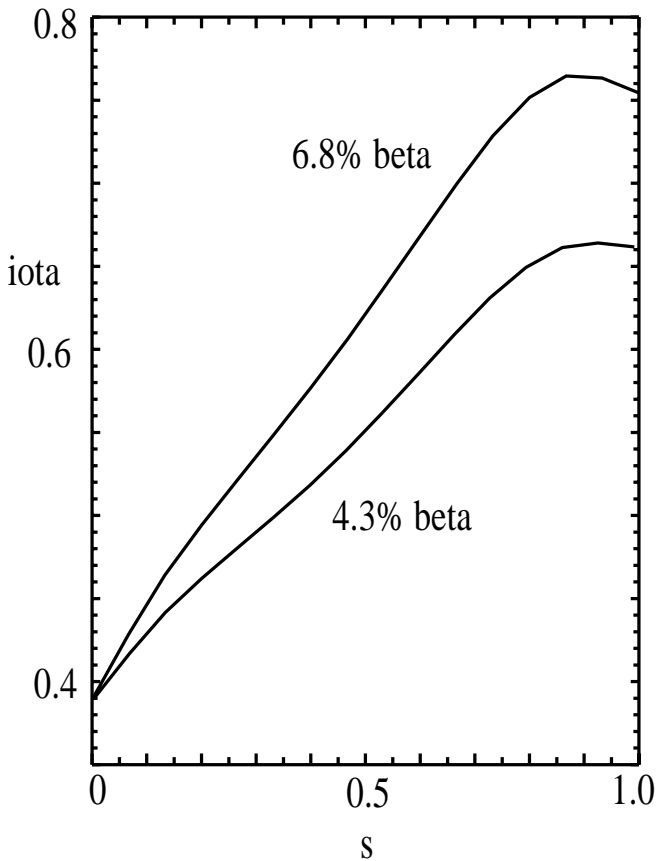

Figure 2. Iota profiles for equilibria above the design point beta.

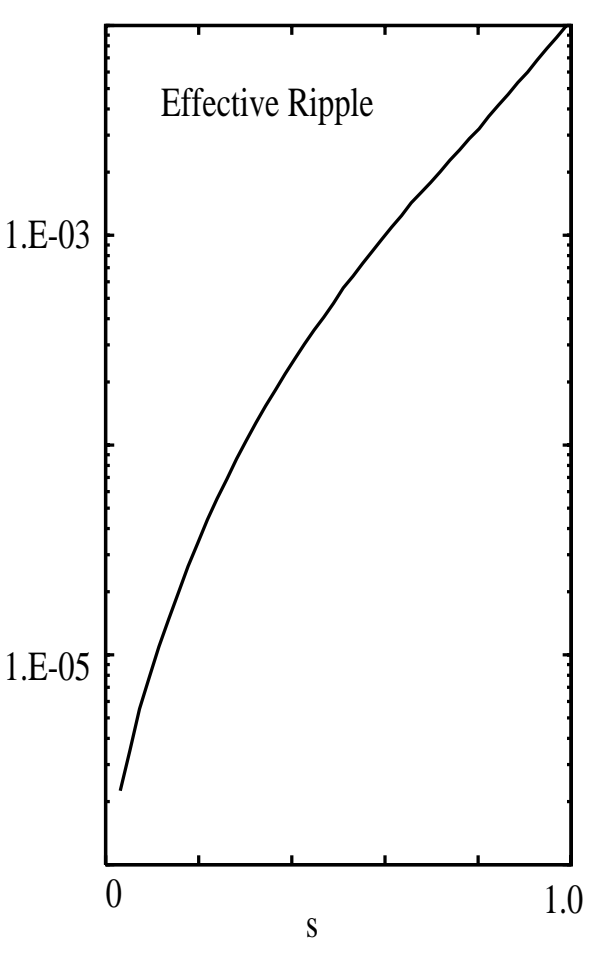

Figure 4. Effective ripple of QAS, calculated with NEO code. 


\section{External Distribution}

Plasma Research Laboratory, Australian National University, Australia

Professor I.R. J ones, Flinders University, Australia

Professor J oão Canalle, Instituto de Fisica DEQ/IF - UERJ , Brazil

Mr. Gerson O. Ludwig, Instituto Nacional de Pesquisas, Brazil

Dr. P.H. Sakanaka, Instituto Fisica, Brazil

The Librarian, Culham Laboratory, England

Library, R61, Rutherford Appleton Laboratory, England

Mrs. S.A. Hutchinson, JET Library, England

Professor M.N. Bussac, Ecole Polytechnique, France

Librarian, Max-Planck-Institut für Plasmaphysik, Germany

J olan Moldvai, Reports Library, MTA KFKI-ATKI, Hungary

Dr. P. Kaw, Institute for Plasma Research, India

Ms. P.J . Pathak, Librarian, Insitute for Plasma Research, India

Ms. Clelia De Palo, Associazione EURATOM-ENEA, I taly

Dr. G. Grosso, Instituto di Fisica del Plasma, Italy

Librarian, Naka Fusion Research Establishment, J AERI, J apan

Library, Plasma Physics Laboratory, Kyoto University, J apan

Research Information Center, National Institute for Fusion Science, J apan

Dr. O. Mitarai, Kyushu Tokai University, J apan

Library, Academia Sinica, Institute of Plasma Physics, People's Republic of China

Shih-Tung Tsai, Institute of Physics, Chinese Academy of Sciences, People's Republic of China

Dr. S. Mirnov, TRINITI, Troitsk, Russian Federation, Russia

Dr. V.S. Strelkov, Kurchatov Institute, Russian Federation, Russia

Professor Peter Lukac, Katedra Fyziky Plazmy MFF UK, Mlynska dolina F-2, Komenskeho Univerzita, SK-842 15 Bratislava, Slovakia

Dr. G.S. Lee, Korea Basic Science Institute, South Korea

Mr. Dennis Bruggink, Fusion Library, University of Wisconsin, USA

Institute for Plasma Research, University of Maryland, USA

Librarian, Fusion Energy Division, Oak Ridge National Laboratory, USA

Librarian, Institute of Fusion Studies, University of Texas, USA

Librarian, Magnetic Fusion Program, Lawrence Livermore National Laboratory, USA

Library, General Atomics, USA

Plasma Physics Group, Fusion Energy Research Program, University of California at San Diego, USA

Plasma Physics Library, Columbia University, USA

Alkesh Punjabi, Center for Fusion Research and Training, Hampton University, USA

Dr. W.M. Stacey, Fusion Research Center, Georgia Institute of Technology, USA

Dr. J ohn Willis, U.S. Department of Energy, Office of Fusion Energy Sciences, USA

Mr. Paul H. Wright, Indianapolis, Indiana, USA 
The Princeton Plasma Physics Laboratory is operated by Princeton University under contract with the U.S. Department of Energy.

\author{
Information Services \\ Princeton Plasma Physics Laboratory \\ P.O. Box 451 \\ Princeton, NJ 08543
}

Phone: 609-243-2750

Fax: 609-243-2751

e-mail: pppl_info@pppl.gov

Internet Address: http://www.pppl.gov 